\title{
COMUNICAÇÃO DA RESPONSABILIDADE SOCIAL NA INTERNET: uma abordagem voltada para o público interno
}

\section{1-Thiago Braga Martins}

Mestrando em Administração pela Universidade de Fortaleza (UNIFOR), Brasil thiagobraga@unifor.br

http://lattes.cnpq.br/7532383260495292

\section{2-Roberta Feitosa de Lucena Cavalcante}

Mestranda em Administração pela Universidade de Fortaleza (UNIFOR), Brasil robertafeitosa@hotmail.com

http://lattes.cnpq.br/4042464250196311

\section{3-José Milton de Sousa Filho}

Doutor em Administração de Empresas pela Fundação Getulio Vargas (EAESP/FGV), Brasil.

Professor do Programa de Pós-Graduação em Administração da Universidade de Fortaleza (PPGA/UNIFOR), Brasil. miltonsousa@unifor.br

http://lattes.cnpq.br/6234417208299902

\author{
Diego Maganhotto Coraiola - Editor Geral \\ Editor responsável pela submissão: \\ Washington José Souza. \\ Artigo analisado via processo de revisão duplo cego (Double-blind). \\ Recebido em: 22/02/2014 \\ Aprovado em: 06/05/2014 \\ Última Alteração: 02/05/2014
}

* Contato Principal: Av. Washington Soares, 1321. Edson Queiroz, Fortaleza - CE, Brasil. CEP: 60.811-905. 


\title{
COMUNICAÇÃO DA RESPONSABILIDADE SOCIAL NA INTERNET: UMA ABORDAGEM VOLTADA PARA O PÚBLICO INTERNO
}

\section{RESUMO}

Este artigo tem o objetivo de identificar as iniciativas voltadas ao público interno (colaboradores), com foco nas ações de responsabilidade social empresarial, comunicadas na internet pelas empresas cearenses classificadas no ranking Great Place to Work 2013. Para tanto, verifica-se o quanto tais empresas, consideradas "modelo" no relacionamento com seus colaboradores, comunicam suas iniciativas voltadas para o público interno em seus websites corporativos e apresenta-se uma proposta de mensuração e avaliação de conteúdo de websites corporativos na divulgação das iniciativas destinadas ao público interno. A abordagem de pesquisa é quantitativa, por verificar a ocorrência de determinados indicadores previamente estabelecidos, e quanto aos fins esta pesquisa é descritiva. No que diz respeito à coleta de dados, trata-se de pesquisa documental, de forma telematizada, através da internet, na medida em que explora e analisa o conteúdo dos websites das 40 melhores empresas para se trabalhar no Ceará. Verificou-se que o indicador mais presente foi o referente à comunicação das premiações recebidas pelo bom relacionamento com o público interno $(86,8 \%)$ e os menos presentes foram os referentes às práticas inclusivas e afirmativas relativas ao colaborador, e à transparência e accountability (relatório social disponível) $(15,8 \%)$.

\section{Palavras-chave}

Responsabilidade social empresarial; Internet; Reputação corporativa; Público interno; Great Place to Work.

\section{COMMUNICATION OF CORPORATE SOCIAL RESPONSIBILITY ON THE INTERNET: AN EMPLOYEE APPROACH}

\begin{abstract}
This article aims to identify initiatives to address workforce (employees), focusing on the actions of corporate social responsibility, communicated on the Internet by companies classified in Great Place to Work 2013 Ceará Ranking. This paper focuses in discover how such companies considered "reference" in relationship with its employees, communicate their initiatives to internal stakeholders on their corporate websites, and to present a proposal for measuring and evaluating the content of disclosure on corporate websites initiatives for the internal audience. The research approach is quantitative and descriptive, to verify the occurrence of certain previously established indicators. With respect to data collection, it is a documentary research, telematic way, over the internet, in that it explores and analyzes the content of the websites of the 40 best companies to work in Ceará. The theoretical dimensions used for data analysis include the areas of corporate social responsibility and corporate reputation. It was found that the indicator was more referring is the announcement of awards received by good relationships with internal stakeholders $(86.8 \%)$ and the least were the gifts related to inclusive and affirmative practice for the developer, and the transparency and accountability (social report available) (15.8\%).
\end{abstract}

\section{Keywords}

Corporate social responsibility; Internet; Corporate reputation; Employees; Great Place to Work. 


\section{Introdução ${ }^{1}$}

Estudos têm demonstrado que a comunicação das ações de responsabilidade social empresarial tende a reforçar a imagem da empresa e a lealdade de seus clientes (Morsing \& Schultz, 2006). É igualmente perceptível que a internet vem ganhando espaço entre as organizações como ferramenta de comunicação e relacionamento, inclusive como meio de divulgação de boas práticas empresariais (Branco \& Rodrigues, 2006; Wanderley et al., 2008). Exemplo dessas boas práticas é a forma como a empresa se relaciona com um de seus principais stakeholders: o público interno (colaboradores).

Em vista disso, observa-se que muitas empresas têm comunicado suas ações de responsabilidade social voltadas ao público interno com a intenção de serem mais bem vistas por todos os seus públicos de interesse. Como a forma pela qual uma empresa se relaciona com seus colaboradores costuma ser de difícil visualização pelo público externo, reconhecimentos outorgados por institutos independentes legitimam a comunicação de boas práticas internas perante seus diversos públicos.

A relevância da chancela concedida por premiações do gênero vai ao encontro do que dizem Aguinis e Glavas (2012) sobre a constatação de que muitas empresas adotam práticas de responsabilidade social empresarial (RSE) puramente simbólicas, apenas para responder na aparência, e não na essência, a pressões de diversas naturezas, fenômeno ao qual se denomina greenwashing ou green fatigue. Para Giavina-Bianchi e Pinedo (2012), deve haver equilíbrio entre o que é feito e o que é comunicado. Aquilo que é comunicado pode sujeitar a empresa à rejeição, caso a distância entre o que se diz e o que se faz seja identificada pelos públicos de interesse.

Em igual sentido, Schlegelmilch e Pollach (2005) citam a comunicação da conquista de prêmios na área de responsabilidade social como ações capazes de incrementar a credibilidade das empresas e evitar os inconvenientes mencionados. Isso coincide com os resultados da pesquisa de Patten e Crampton (2004) quanto à necessidade de certificação por um instituto especializado e independente para que se garanta a credibilidade da comunicação. Jahdi e Acikdilli (2009) acrescentam que, no site da empresa, hyperlinks que direcionam o usuário para organizações confiáveis são desejáveis para reforçar ao público a veracidade das informações comunicadas.

Criada em 1988, o Great Place to Work (GPTW) é uma instituição global especializada em excelência no ambiente de trabalho através de rankings que identificam e classificam as melhores empresas para trabalhar no mundo. Em 1997, as revistas Fortune (EUA) e Exame (Brasil) uniram-se ao GPTW para produzir as primeiras listas da premiação “100 Melhores Empresas para Trabalhar". No Brasil, a partir de 2006, a lista nacional passou a ser publicada pela revista Época e as listas regionais são publicadas em parceria com outros veículos. No Ceará, a lista é publicada em conjunto com o Grupo de Comunicação O Povo (GPTW, 2013). Atualmente, as listas de melhores empresas para trabalhar do GPTW estão presentes em 49 países.

Dessa forma, a relevância da comunicação da responsabilidade social, incluindo as ações direcionadas aos colaboradores para incremento de imagem da empresa junto a seus públicos de interesse, e o papel da internet como eficaz ferramenta de comunicação empresarial coadunam na realização desta pesquisa, que pretende responder à seguinte questão: Quais iniciativas voltadas ao público interno, especialmente ações de RSE, são comunicadas pelas empresas na internet?

Considerando, adicionalmente, a aludida importância para a empresa de ser bem avaliada por premiações no campo da RSE, o objetivo geral desta pesquisa é: Investigar as iniciativas de RSE voltadas ao público interno divulgadas nos websites das empresas cearenses classificadas no ranking Great Place to Work 2013. Para suportar o objetivo geral, foram vislumbrados os seguintes objetivos específicos: (a) verificar o quanto as empresas cearenses que se destacam pela boa maneira como tratam seus colaboradores comunicam suas iniciativas voltadas para o público interno em seus websites; e (b) apresentar uma proposta de mensuração e avaliação dos conteúdos de websites corporativos na divulgação das iniciativas destinadas ao público interno.

A contribuição desta pesquisa possui caráter científico e prático, já que contempla a proposição de um novo modelo de indicadores para mensurar e avaliar conteúdos de websites corporativos, conforme expresso nos objetivos específicos, assim como atende à lacuna teórica/empírica de pesquisas sobre comunicação de iniciativas voltadas ao público interno, notadamente ações de RSE, por meio de websites corporativos; difunde iniciativas voltadas ao público interno consideradas eficazes, uma vez que são praticadas por “empresas modelo" no relacionamento com seus colaboradores; e cria um ponto de partida para pesquisas mais detalhadas sobre o tema em questão, que englobarão descrição das principais práticas adotadas e análise de outros recursos da internet - redes sociais, por exemplo - ou para pesquisas mais amplas, com a análise das 100 melhores empresas brasileiras para se trabalhar (Great Place to Work Brasil), seguindo a mesma linha de investigação. O conhecimento aqui apresentado pode servir, assim, tanto a pesquisadores das ciências administrativas na área de comunicação da RSE quanto a gestores de empresas que buscam informações na referida área. 


\section{Referencial Teórico}

\subsection{Comunicação da Responsabilidade Social Empresarial pela Internet}

A RSE tem sido objeto de estudo frequente ao longo das últimas décadas (Davis, 1960; Carroll, 1979; 1991; 1999; Wood, 1991) e é um conceito de negócio que diz respeito à importante relação entre empresas e sociedade (Carroll, 1999), definida pela integração entre as práticas empresariais e padrões mais elevados de convivência em sociedade, preservando a rentabilidade (Hopkins, 2007). Baseia-se na ideia de que as empresas são mais do que apenas entidades que buscam o lucro, na medida em que são responsáveis pelos efeitos sociais e ambientais de suas atividades (Lantos, 2001).

Para Harrison (2005), a empresa deve considerar os diversos públicos de interesse em seu planejamento, especialmente os internos, para obter desempenho superior no longo prazo. Barbieri e Cajazeira (2009) corroboram tal ponto de vista ao enfatizar que as empresas devem interagir com seus colaboradores através do diálogo e da participação nas estratégias da gestão. Participação esta destacada por Spitzeck, Hansen e Alt (2011) no que eles chamam de capacidade organizacional de engajamento com stakeholders, que consiste no aprendizado conquistado nos relacionamentos. Como forma de aumentar colaborações, evitar confrontos e diminuir dúvidas em processos decisórios, os autores sugerem ainda que se alinhem os pensamentos de quem está dentro e fora da organização, criando-se dessa maneira uma relação de confiança entre os sujeitos envolvidos (Spitzeck, Hansen \& Alt, 2011).

Para que as ações socialmente responsáveis de uma empresa convertam-se mais facilmente em valor ante os stakeholders, recomenda-se sua divulgação junto a tais públicos de interesse, conforme se pode depreender de estudos publicados a respeito (Morsing \& Schultz, 2006; Schlegelmilch \& Pollach, 2005). A ISO 26.000 (ABNT, 2010, p. 78-79), na subseção intitulada "Comunicação sobre responsabilidade social", aponta uma série de razões que evidenciam a relevância de se comunicar as práticas de RSE:

[ ...] mostrar como a organização está cumprindo seus compromissos de responsabilidade social e respondendo aos interesses das partes interessadas e às expectativas da sociedade em geral; [...] ajudar a engajar e motivar empregados e outros para apoiar as atividades de responsabilidade social da organização; [...] e fortalecer a reputação da organização no que se refere à ação responsável, franqueza, integridade e accountability, para fortalecer a confiança das partes interessadas na organização.

Diante da crescente demanda das partes interessadas por maior transparência, as empresas buscam adotar uma comunicação de RSE mais proativa, indo além das exigências legais. Nesse sentido, Laville (2009) amplia o campo da comunicação da RSE para outras ações sustentáveis através da identificação de quatro eixos: (a) apoiar causas consideradas relevantes por seus públicos de interesse; (b) informar a opinião pública sobre possíveis riscos inerentes a sua área de atuação; (c) promover um comportamento responsável do consumidor; (d) esclarecer o consumidor a distinguir os produtos e seus atributos para que possam julgar, comparar e comprar melhor.

Convém aqui relacionar à comunicação de RSE a teoria da legitimidade, a qual se baseia na ideia de que "existe uma espécie de contrato social entre as organizações e a sociedade em que atuam, representando um conjunto de expectativas de seus membros a respeito da forma como elas devem operar" (Dias Filho, 2007, p. 6). Visão endossada por Silva e Sancovsch (2006), ao afirmarem que a teoria da legitimidade e a hipótese do custo político ajudam a explicar o aumento da evidenciação social, sobretudo quando há pressão pública sobre as empresas para ser, ou parecer, mais responsáveis nos campos social e ambiental. De acordo com Birth et al. (2008), a comunicação da RSE tem justamente o objetivo de legitimar o comportamento da empresa mediante a divulgação de informações que exerçam influência positiva na mente dos stakeholders.

A respeito da comunicação de RSE na internet, Morsing (2006) a define como a comunicação elaborada e difundida pela própria organização sobre suas ações de responsabilidade social. Para Du, Bhattacharya \& Sen (2010), a comunicação na internet oferece a oportunidade de se envolver e compartilhar informações com vastas audiências. Ao dedicar uma seção do site da empresa à RSE, por exemplo, pode-se incorporá-la às redes sociais e convidar o visitante a se juntar à empresa em apoio a uma determinada causa (Du, Bhattacharya \& Sen, 2010). Assim, são muitos os motivos que tornam a temática 'comunicação da RSE pela internet' importante, haja vista que já ocupa espaço relevante na agenda de pesquisa internacional (Capriotti \& Moreno, 2007; Chaudhri \& Wang, 2007; Tang \& Li, 2009; Wang \& Chaudhri, 2009; Meyskens \& Paul, 2010; Mohammed, Alwi \& Jamil, 2010; Bayoud, Kavanagh \& Slaughter, 2010; Hamayoun et al., 2012; Chapple \& Moon, 2005; Wanderley et al., 2008; Kim \& Nam, 2012).

Entre os atrativos relativos à comunicação oferecidos pela internet, Adams e Frost (2004) destacam os seguintes: (a) mensuração das seções mais visitadas e das visitas recebidas à página; (b) download e edição da informação pelo usuário; (c) acessibilidade a qualquer tempo e lugar em que haja conexão à internet; (d) possibilidade de atualizações frequentes e informações em tempo real; (e) indexação para facilitar a identificação dos documentos relevantes; e (f) a possibilidade de fornecer diálogo e informação específica, detalhada, de acordo com as exigências dos stakeholders. Por outro lado, enumeram desvantagens da comunicação no ambiente virtual: (a) informações não auditadas nem verificadas com rigor, o que diminui a credibilidade; (b) veiculação de informação em excesso e de modo desordenado; (c) necessidade de recursos para desenvolver e manter uma página web; e (d) exclusão digital, ou seja, nem todos acessam a internet.

Entre pontos positivos e negativos, Wurman (2005) destaca que as empresas ainda estão se ajustando aos canais de informação da internet, a partir do esforço que ele chama de formatação de informação. 0 autor 
lista noções que as companhias devem levar em conta no mundo conectado para ter êxito na comunicação online: (a) saber para que serve a informação divulgada; (b) organizar a informação (isto é, encontrá-la, filtrá-la, classificá-la e marcá-la) tão bem quanto se elabora seu conteúdo; (c) entender que o mundo é seu mercado; e (d) integrar informação, quer dizer, sincronizá-la a outros canais de comunicação online e offline e atualizá-la periodicamente.

Tais cuidados servem para melhorar a comunicação das empresas pela internet, e, nesse âmbito, a divulgação de sua RSE busca informar aos stakeholders suas ações e políticas na área, bem como melhorar sua imagem e reputação.

\subsection{Reputação Corporativa}

Reputação corporativa trata-se de um bem intangível construído pelas pessoas que compõem uma empresa por meio das experiências de consumo de seus produtos ou serviços, dos resultados para a sociedade de suas atividades e da comunicação organizacional empreendida, o que pode resultar em incremento de marca e do valor de suas ações (Vance \& Ângelo, 2007).

Investimentos em reputação são potenciais geradores de vantagens internas, no desenvolvimento de capacidades fundamentais como cultura corporativa e know-how. Corresponde a um recurso passível de ser criado ou destruído em decorrência da escolha de implementar ou não atividades relativas à RSE e sua posterior comunicação. As companhias que gozam de boa reputação em responsabilidade social teriam mais chances de estabelecer relacionamentos com parceiros relevantes e atrair melhores colaboradores, além de aumentar a lealdade e o comprometimento de seu público interno (Branco \& Rodrigues, 2006).

Pesquisadores na área de estratégia entendem reputação como um recurso interno diferenciador e capaz de gerar vantagens competitivas, enquanto pesquisadores nas áreas de marketing, relações públicas e comunicação têm apontado a reputação empresarial como elemento crucial para aumentar a venda de produtos e serviços, entre outras vantagens (Sousa-Filho, Abreu \& Wanderley, 2007). De modo complementar, Pearce II e Doh (2005) destacam que a responsabilidade corporativa tem crescido em importância na agenda dos executivos, haja vista que através dela é possível incrementar imagem e reputação de uma organização.

Garriga e Melé (2004) argumentam que a reputação da empresa é pautada com o consentimento da comunidade na qual ela opera. Segundo Barakat (2013), a reputação é construída e mantida pela capacidade da empresa em atender às expectativas dos múltiplos stakeholders. Estudos empíricos, como o de Zyglidopolous (2001), demostram que existe uma relação positiva entre reputação e desempenho financeiro, sendo aquela influenciadora desta.

Kotler e Caslione (2008) lançam algumas questões provocativas sobre a dimensão da reputação sob uma perspectiva de futuro: a reputação da empresa entre as partes interessadas contribui para aumentar as chances de prosperidade duradoura? Como a empresa será capaz de entusiasmar seus clientes a ponto de convertê-los em propagandistas de seus produtos e serviços? A prática ativa da responsabilidade social aumenta a longevidade da organização?

Embora pareça não haver respostas conclusivas a respeito, estudos apontam que os resultados positivos decorrentes da boa reputação costumam vir no longo prazo. É o que apontam Giavina-Bianchi e Pinedo (2012) em investigação que avaliou a relevância da responsabilidade social na escolha de produtos e serviços por consumidores brasileiros. O resultado mostrou que esse fator impacta de forma pronunciada no momento em que as pessoas estão formando sua impressão sobre a marca, mas não tanto na hora da compra, concluindo que seria mais efetivo concentrar investimentos em ações que impactem em como os consumidores se engajam e se envolvem com as empresas do que no processo de decisão de compra em si.

Stanley (2011) cita pesquisa realizada em 2010 com mais de 200 empresas que apresentou uma relação de erros corporativos em suas políticas de incremento de imagem, como por exemplo: (a) dissociação do core business; (b) falta de realismo; (c) incoerência de governança; (d) falta de mensuração; (e) viés unidimensional sem compreender a interdependência entre as dimensões social, econômica e ambiental; e (f) comunicação ineficiente, seja pela falta dela ou porque as empresas ainda parecem oportunistas aos olhos de muitos.

Scarlett (2011) discorre sobre a necessidade de elevar o nível de congruência entre as atividades da empresa e a causa por ela adotada. Essa congruência é o sentido lógico da conexão entre a função de negócios da empresa e a tal causa. Se existe conexão clara (high-fit), as pessoas estão mais propensas a assimilar positivamente as ações de RSE; do contrário (low-fit), podem tornar-se céticas em relação às motivações de tais ações.

Para conquistar mais do que admiração, e sim resultados efetivos, as iniciativas comunicadas devem ser coerentes com o posicionamento cristalizado da instituição na mente do consumidor e ser consistentes, e não isoladas (Sisodia, Sheth \& Wolfe, 2012). Ainda segundo os autores, tais iniciativas devem estar alinhadas com sua essência, seus valores, seus propósitos; devem deixar de ser atribuições de um departamento específico para se tornar premissas em todos os processos, incorporando boas práticas às estratégias e por toda a cadeia de valor. E devem, finalmente, conforme já explicitado neste artigo, chegar ao conhecimento de seus públicos, pois um valor não percebido é apenas um valor em potencial desperdiçado. 


\section{Procedimentos Metodológicos}

Sob uma abordagem quantitativa, esta pesquisa verifica a ocorrência de 13 indicadores previamente estabelecidos, sem aprofundamento em sua análise, através da observação de uma ou mais variáveis independentes (categóricas ou métricas) sobre uma variável dependente dicotômica, representando a presença (1) ou ausência (0) de uma característica (Hosmer \& Lemeshow, 1989; Hair et al., 2005).

Quanto aos fins, trata-se de pesquisa descritiva e exploratória (Cooper \& Schindler, 2003; Gil, 1989), investigando um fenômeno pouco pesquisado até o momento - a comunicação pela internet de iniciativas direcionadas ao público interno. Cooper e Schindler (2003, p. 136) entendem que na pesquisa descritiva "devem ser realizadas descrições de fenômenos [...] e descoberta de associações entre as diferentes variáveis".

\begin{tabular}{|l|}
\hline \multicolumn{1}{|c|}{ Indicadores } \\
\hline 1. Benefícios de bem-estar do colaborador (assistência \\
médica, odontológica, psicológica, alimentar ou de \\
transporte, atividades recreativas, etc.).
\end{tabular}
transporte, atividades recreativas, etc.).

2. Projetos de qualificação do colaborador (cursos, treinamentos, campanhas de esclarecimento ou conscientização, etc.).

3. Projetos de voluntariado do colaborador (doação de sangue ou de donativos, plantio de árvores, visita a instituições de caridade, etc.).

4. Projetos destinados a dependentes do colaborador.

5. Projetos destinados a terceirizados, estagiários e parceiros

6. Práticas inclusivas e afirmativas relativas ao colaborador (políticas de equidade de gênero e de contratação de deficientes, negros, ex-presidiários, etc.).

7. Plano de carreira e programa de participação nos resultados.

8. Menção na página inicial a iniciativas destinadas ao público interno.

9. Menção nas informações institucionais (missão/visão/valores) à importância do público interno.

10. Recursos de mídia e comunicação com o público interno (mural, intranet, jornal, reuniões temáticas, programa de TV ou rádio, etc.)

11. Premiações referentes ao bom relacionamento com o público interno.

12. Transparência e accountability (relatório social disponível).

13. Informações sobre seleção ou contratação de novos colaboradores.

Figura 1 - Indicadores de avaliação dos websites e suas referências

Fonte: Autoria própria com base em autores diversos.

No que diz respeito à coleta de dados, a pesquisa é documental, de forma telematizada, através da internet (Sousa-Filho, Wanderley \& Farache, 2010), por explorar e analisar os websites das 40 (quarenta) melhores empresas para se trabalhar no Ceará, segundo classificação do prêmio Great Place to Work (GPTW). A
1. Adaptado de Instituto Ethos (2007): "Indicador 16 Cuidados com Saúde, Segurança e Condições de Trabalho"; e de Wanderley et al. (2008): "Indicador 2 - Informações relevantes sobre projetos sociais e ambientais".

2. Adaptado de Instituto Ethos (2007): "Indicador 17 Empregabilidade".

3. Autoria própria, a partir da percepção de que é comum a empresa buscar engajar seus colaboradores em seus projetos de voluntariado.

4. Autoria própria, a partir da percepção de que a família tem se constituído parte integrante dos públicos internos da empresa ao receber atenção por parte desta em sua comunicação e seus projetos.

5. Adaptado de Instituto Ethos (2007): "Indicador 14 Relações com Trabalhadores Terceirizados".

6. Adaptado de Instituto Ethos (2007): "Indicador 11 Valorização da Diversidade; Indicador; Indicador 12 Compromisso com Não-Discriminação e Promoção da Equidade Racial: Indicador 13 - Compromisso com a Promoção da Equidade de Gênero".

7. Adaptado de "Instituto Ethos (2007): Indicador 15 - Política de Remuneração, Benefícios e Carreira".

8. Adaptado de Wanderley et al. (2008): "Indicador 7: Expressão RSC ou expressão semelhante (desenvolvimento sustentável ou responsabilidade ambiental) na página inicial do site corporativo"

9. Adaptado de Wanderley et al. (2008): "Indicador 6: Valores corporativos".

10. Adaptado de França, Favoretto \& Braga (2011): "Indicador 4 - Recursos avançados de Mídia e Comunicação".

11. Autoria própria, a partir da percepção de que prêmios podem atestar perante os diversos públicos da empresa que esta mantém um bom relacionamento com seus colaboradores.

12. Adaptado de França, Favoretto \& Braga (2011): "Indicador 3 - Transparência e Accountability"; e de Wanderley et al. (2008): "Indicador 5 - Relatório social".

13. Autoria própria, a partir da percepção de que a empresa, ao divulgar tal tipo de informação, mostra-se disposta a captar novos talentos para incrementar seu quadro funcional e acessível a quem se sinta atraído a trabalhar nela. Compromisso com o Desenvolvimento Profissional e a 
coleta de dados abrangeu os meses de novembro e dezembro de 2013. A entrega do prêmio ocorreu no dia 18 de outubro de 2013, na cidade de Fortaleza/CE. As cinco melhores empresas foram anunciadas por ordem de colocação: 1a - B\&Q Energia; 2a - Consórcio Nacional Embracon; 3ạ - SJ Administração de Imóveis; 4 o - Ceará Diesel; 5ㅇ - Newland Veículos (GPTW, 2013).

As 107 empresas cearenses inscritas no GPTW 2013 enviaram as pesquisas solicitadas pelo Instituto GPTW nos meses de maio e junho de 2013. Após análise, a avaliação das empresas foi feita nos meses de julho, agosto e setembro de 2013, de acordo com os critérios de credibilidade, respeito, imparcialidade, orgulho e camaradagem dentro da empresa (GPTW, 2013).

O universo da pesquisa foram as ações de RSE voltadas para o público interno, bem como ações de RH comunicadas pelas empresas cearenses em seus websites, aplicados numa amostragem não probabilística das 40 Melhores Empresas para Trabalhar 2013 - Ceará, classificadas no ranking GPTW. A lista de empresas cujos websites foram investigados consta no Apêndice A.

A análise dos dados deu-se através da análise de conteúdo mediante a verificação do atendimento a 13 variáveis previamente estabelecidas. A análise de conteúdo constitui um conjunto de técnicas de análise de comunicação visando obter, por objetivos de descrição do conteúdo das mensagens, indicadores (quantitativos ou não) que permitam a inferência de conhecimentos relativos às condições de produção e recepção destas mensagens (Bardin, 2009).

Por meio da análise de conteúdo, foi descrito e interpretado o conteúdo dos websites das 40 melhores empresas para se trabalhar no Ceará, no que concerne à comunicação das iniciativas voltadas ao público interno, especialmente ações de responsabilidade social. Os indicadores constam no Quadro 1, acompanhados da respectiva referência do trabalho em que foram utilizados de modo semelhante:

Os indicadores 3, 4, 11 e 13 que constam na Figura 1, são de autoria própria e foram criados a partir da percepção dos presentes autores sobre sua importância na prática de comunicação das empresas, principalmente no que diz respeito ao público interno. Tais indicadores ainda não foram utilizados em estudos anteriores, assim poder-se-á constatar sua adequação e importância a partir desta pesquisa.

A análise dos dados verificou a incidência de cada um desses indicadores nos websites corporativos e computou a frequência em números percentuais, conforme se vê na seção seguinte.

\section{Resultados e Discussão}

Após concluir as visitas aos websites e tabular os dados, é o momento de apresentar os resultados e confrontá-los com o referencial teórico. Inicialmente, uma ressalva: as empresas Hidracor e KLC não foram avaliadas porque o site da primeira empresa estava fora do ar na ocasião da pesquisa e a segunda empresa não possui site.

Portanto, a amostra foi reduzida de 40 para 38 websites. A seguir, demonstra-se na Tabela 1 a incidência dos indicadores nos sites pesquisados, dispostos em ordem decrescente de frequência.

Tabela 1

Frequência com que iniciativas voltadas ao público interno são comunicadas pelas empresas pesquisadas no website Iniciativas voltadas ao público interno comunicadas no website Frequência (\%)

11. Premiações pelo bom relacionamento com o público interno

86,8

13. Informações sobre seleção/contratação de novos colaboradores

10. Recursos de mídia e comunicação com o público interno

9. Menção em missão/visão/valores à importância do público interno

2. Projetos de qualificação do colaborador

8. Menção na página inicial a iniciativas destinadas ao público interno

1. Benefícios de bem-estar do colaborador

3. Projetos de voluntariado do colaborador

5. Projetos destinados a terceirizados, estagiários e parceiros

4. Projetos destinados a dependentes do colaborador

7. Plano de carreira e programa de participação nos resultados

6. Práticas inclusivas e afirmativas relativas ao colaborador

12. Transparência e accountability (relatório social disponível)

Fonte: Autoria própria com base em dados da pesquisa Great Place to Work 2013 , disponível em: <http://www.greatplacetowork.com.br/melhores-empresas/gptw-ceara>

O indicador mais recorrente (Premiações) sugere que a grande maioria das empresas classificadas no ranking GPTW busca gerar valor ante seus públicos de interesse, internos e externos, com a divulgação do reconhecimento à boa maneira com que se relaciona com seus colaboradores, como forma de incrementar sua reputação de organização socialmente responsável. Conforme se viu aqui, a atenção aos colaboradores constitui um dos pilares da RSE e esta é uma maneira de gerar boa reputação (Pearce II \& Doh, 2005), bem como a chancela de um prêmio legitima a comunicação de boas práticas de uma empresa (Schlegelmilch \& Pollach, 2005). 
O segundo indicador mais verificado (Informações sobre seleção/contratação), combinado ao primeiro, sugere que o reconhecimento pela boa relação com o público interno é fator de atração para candidatos a vagas na empresa, razão pela qual convites como "Trabalhe aqui" sejam tão frequentes no website das empresas pesquisadas. Tal fenômeno é confirmado por Branco e Rodrigues (2006) quando apontam que empresas de boa reputação conseguem atrair melhores colaboradores, assim como aumentar a lealdade e o comprometimento daqueles que lá trabalham. Além de incrementar a capacidade de atração da organização como potencial empregadora, Keeler (2003) constatou que sua boa visibilidade constitui-se como ferramenta de controle para limitar a rotatividade de pessoal.

O terceiro indicador (Recursos de mídia e comunicação) relaciona-se com a importância de manter canais abertos de comunicação com os colaboradores em todos os níveis, a fim de deixá-los informados do que ocorre na empresa e dar-Ihes voz por meio da comunicação ascendente, o que pode fazê-los sentirem-se prestigiados e, portanto, mais satisfeitos em seu trabalho. Scarlett (2011) sublinha que a comunicação interna pode ocorrer através de diversos canais, incluindo house-organs (publicações internas), mural, boletins informativos, intranet, e-mail e portal eletrônico. Para Barbieri e Cajazeira (2009), as empresas também devem interagir com seus colaboradores pelo diálogo e participação nas estratégias.

O quarto indicador (Menção em missão/visão/valores) faz referência à atenção que a empresa presta a seus colaboradores em seus princípios. Embora não seja garantido que tudo se realize na prática, pode-se inferir que boas práticas são efetivadas após serem concebidas em teoria e intenções. Segundo Birth et al. (2008), missão, visão e valores da empresa estão entre os temas de RSE que podem ser comunicados, ao lado de ambiente de trabalho, diálogo social, direitos humanos, desenvolvimento da economia local, meio ambiente e relações éticas com o mercado.

O quinto indicador (Projetos de qualificação) trata-se, enfim, do primeiro mais diretamente relacionado a projetos de RSE. É natural ser esta a ação de RSE mais praticada, ou pelo menos divulgada, já que a qualificação dos colaboradores pode ser entendida como a mais passível de ser revertida em ganho imediato para a empresa em virtude de esta passar a contar com profissionais mais capacitados em seu quadro. Scarlett (2011) observa que iniciativas dessa natureza podem causar nos funcionários uma sensação de orgulho que os acompanha para além dos muros da empresa, convertendo-os em potenciais embaixadores da marca, o que vem a ser um trunfo promocional para a empresa.

O indicador seguinte (Menção na página inicial) assemelha-se ao indicador que ocupa a primeira posição do ranking (Tabela 1), no que diz respeito à relevância que se dá à maneira como se trata o público interno na tentativa de se gerar valor. Conforme Dawkins e Lewis (2003), a alta consideração destinada aos colaboradores justifica-se porque estes, quando conscientes de que trabalham para uma organização que investe em ações responsáveis, mostram-se mais satisfeitos e compromissados. Os autores demonstraram que $65 \%$ dos funcionários são mais inclinados a gerar boca a boca positivo em torno de sua empresa quando informados sobre as iniciativas de responsabilidade social.

Em seguida, temos o último indicador (Benefícios de bem-estar) presente na maioria dos websites analisados. A exemplo do quinto indicador, este também se trata de ação de RSE, esta das mais abrangentes por contemplar um grande número de iniciativas possíveis. Inclusive, esperava-se que esse fosse um indicador mais presente nos websites, já que tais benefícios podem levar a um aumento da disponibilidade de tempo e energia dos funcionários para suas empresas e candidatos são mais atraídos por empresas com altos índices de RSE (Maignan \& Ferrell, 2004).

Os indicadores posteriores, conforme dito, foram encontrados na minoria dos websites, havendo um empate entre os dois últimos (Práticas inclusivas e afirmativas; Transparência e accountability), o que mais uma vez não é de se espantar, tendo em vista que tais iniciativas exigem um grau maior de desprendimento e transparência por parte da empresa. De todo modo, é acentuada a diferença para os resultados obtidos em outras pesquisas: em França, Favoretto \& Braga (2011) e Sousa-Filho, Wanderley e Farache (2010), por exemplo, todas as companhias examinadas disponibilizavam os relatórios anuais de responsabilidade social - a que pesem os diferentes tipos de empresas analisadas em cada artigo.

Na Tabela 2, vê-se o desempenho individual das empresas no tocante ao atendimento dos indicadores desta pesquisa.

Percebe-se que pouco menos da metade das empresas (17 das 38) atingiu um percentual superior a $50 \%$ de indicadores atendidos, situando-se as demais abaixo desse índice. Tal resultado surpreende, considerando o potencial que tais empresas possuem para realizar iniciativas relevantes junto ao público interno e comunicar tais iniciativas. Como sugestões de futuras pesquisas, tem-se: investigar a recepção da comunicação das ações internas de RSE pelo público externo; verificar a correlação entre a colocação no ranking (Tabela 2) e o setor de atuação ou o tamanho da empresa; focalizar a comunicação de RSE nas redes sociais, especialmente Facebook e Twitter; avaliar o impacto da divulgação de informações relacionadas à atenção ao público interno no aumento da credibilidade da empresa perante seus públicos de interesse.

Como contribuição prática para as empresas em geral, os resultados aqui apresentados apontam, no caso dos indicadores localizados nas primeiras posições, quais iniciativas convêm ser realizadas e comunicadas a fim de se equiparar e fazer frente àquelas empresas que já se destacam na atenção ao público interno, bem como sinalizam, no caso dos indicadores localizados nas últimas posições, quais iniciativas convêm ser realizadas e comunicadas para se diferenciar e assim sair na frente mesmo em relação a empresas que já 
possuem uma atuação destacada na atenção ao público interno, uma vez que são práticas ainda a serem devidamente exploradas.

Tabela 2

Ranking das empresas mais bem classificadas no atendimento aos indicadores de comunicação de iniciativas voltadas ao público interno no website

\begin{tabular}{|c|c|c|}
\hline Colocação & Empresas & Frequência (\%) \\
\hline $1 \underline{a}$ & $\begin{array}{l}\text { Cerbras } \\
\text { Consórcio Nacional Embracon } \\
\text { Mercadinhos São Luiz }\end{array}$ & 84,6 \\
\hline $4 \underline{a}$ & $\begin{array}{l}\text { Amêndoas do Brasil } \\
\text { Construtora Marquise } \\
\text { Instituto Dom José de Educação e Cultura (IDJ) } \\
\text { Ivia } \\
\text { Via Urbana }\end{array}$ & 76,9 \\
\hline 9a & $\begin{array}{l}3 \text { corações } \\
\text { Acal } \\
\text { Aliança } \\
\text { Casablanca Turismo } \\
\text { Coelce } \\
\text { Cosampa Projetos e Construções } \\
\text { Eficaz Engenharia e Serviços } \\
\text { Unicred Fortaleza }\end{array}$ & 69,2 \\
\hline $17 \underline{a}$ & Ceneged & 53,8 \\
\hline $18^{a}$ & $\begin{array}{l}\text { B\&Q Energia } \\
\text { Conecta Serviços } \\
\text { Polibrasnet } \\
\text { SJ Administração de Imóveis } \\
\text { Sucos Jandaia }\end{array}$ & 46,1 \\
\hline 23 a & $\begin{array}{l}\text { Ceará Diesel } \\
\text { Cobap } \\
\text { Fortbrasil } \\
\text { Free Life Saúde } \\
\text { Synapsis Brasil }\end{array}$ & 38,5 \\
\hline $28 \underline{a}$ & $\begin{array}{l}\text { Endicon Engenharia } \\
\text { Grupo Geppos } \\
\text { Magis Incorporações } \\
\text { Siqueira Castro Advogados } \\
\text { Unimed Ceará }\end{array}$ & 30,8 \\
\hline $33 a$ & $\begin{array}{l}\text { Newland Veículos } \\
\text { Saga }\end{array}$ & 23,1 \\
\hline 35 a & Ibyte & 15,4 \\
\hline $36 \underline{a}$ & $\begin{array}{l}\text { Beach Park } \\
\text { Dafonte Veículos } \\
\text { SM Fomento Comercial }\end{array}$ & 7,7 \\
\hline
\end{tabular}

<http://www.greatplacetowork.com.br/melhores-empresas/gptw-ceara>

\section{Conclusão}

O presente trabalho identificou as iniciativas voltadas ao público interno, com foco nas ações de RSE, comunicadas na internet pelas empresas cearenses classificadas no ranking Great Place to Work 2013 . Tais iniciativas foram aqui identificadas e classificadas conforme o grau de ocorrência nos websites das empresas classificadas no referido ranking.

Verificou-se o quanto tais empresas, consideradas "modelo" no relacionamento com seus colaboradores, comunicam suas iniciativas voltadas para o público interno em seus websites corporativos. Para tanto, criou-se aqui um novo ranking das empresas classificadas no GPTW para mensurar o quanto cada uma comunica em seus websites as mencionadas iniciativas.

Os indicadores 13 (Informações sobre seleção/contratação de novos colaboradores) e 11 (Premiações pelo bom relacionamento com o público interno) foram propostos pelos presentes autores (indicadores inéditos e de autoria própria), e também foram aqueles com maior incidência nos websites das empresas pesquisadas, 
$86,8 \%$ e $84,2 \%$ respectivamente. Tal achado mostra a adequação e a importância dos indicadores propostos para analisar o fenômeno, e assim, se configuram como uma contribuição teórico-empírica prestada por este trabalho. Além disso, os outros dois indicadores, 3 (Projetos de voluntariado do colaborador) e 4 (Projetos destinados a dependentes do colaborador) também se mostraram adequados, porém com menor percentual de incidência, $42,1 \%$ e $23,7 \%$ respectivamente.

Apresentou-se, enfim, uma proposta de mensuração e avaliação de conteúdo de websites corporativos na divulgação das iniciativas destinadas ao público interno, a qual contempla indicadores inéditos e outros adaptados de pesquisas relativas à comunicação pela internet das ações de responsabilidade empresarial. A perspectiva de análise deu-se sobre referencial teórico a respeito de comunicação de responsabilidade social empresarial na internet e reputação corporativa.

Um ponto comum observado entre os websites das empresas mais bem colocadas no ranking elaborado por esta pesquisa (Tabela 2) é a presença de um ambiente virtual dedicado a notícias, o qual pode ser atualizado constantemente com iniciativas de interesse da empresa e gerar visitações sistemáticas pela publicação regular de novos conteúdos. Algumas empresas pesquisadas, como Synapsis, Via Urbana e Mercadinhos São Luiz, apresentavam inclusive uma página no site inteiramente destinada ao colaborador, permitindo descrever com profundidade e amplitude as iniciativas relacionadas ao público interno.

Entre as iniciativas mais engenhosas, sobressaem o bloco de carnaval na cidade do Recife formado por funcionários da Ivia; o projeto da empresa 3 Corações que abre suas fábricas para visitação, integrando colaboradores e membros da comunidade; o São João solidário da Casablanca Turismo, que não só angaria recursos materiais, mas promove também coleta de sangue e doação de medula óssea; a Biblioteca Itinerante da Cerbras em parceria com o Sesi; o projeto da Marquise de alfabetização de adultos e sua oficina de leitura e inclusão digital nas obras.

Assim, procede-se ao cumprimento dos objetivos geral e específicos desta pesquisa. As principais contribuições que esta investigação pretende fornecer, além da já mencionada proposição de novo modelo de indicadores para mensurar e avaliar conteúdos de websites corporativos, são as seguintes: atendimento à lacuna teórica/empírica de pesquisas sobre comunicação de iniciativas voltadas ao público interno, notadamente ações de RSE, por meio de websites corporativos; difusão de iniciativas voltadas ao público interno consideradas eficazes, uma vez que são praticadas por "empresas modelo" no relacionamento com seus colaboradores; e criação de ponto de partida para pesquisas mais detalhadas sobre o tema em questão, que englobarão descrição das principais práticas adotadas e análise de outros recursos da internet - redes sociais, por exemplo - ou para pesquisas mais amplas, com a análise das 100 melhores empresas brasileiras para se trabalhar (Great Place to Work Brasil), por exemplo, seguindo a mesma linha de investigação.

\section{Notas}

1. Os autores gostariam de agradecer aos dois avaliadores anônimos pelas contribuições e recomendações, estas melhoraram a qualidade da versão final deste trabalho

\section{Referências}

ABNT (2010). ABNT NBR ISO 26000. Diretrizes sobre responsabilidade social.

Adams, C. A.; Frost, G. R. (2004). The Development of Corporate Web-sites and Implications for Ethical, Social and Environmental Reporting through these Media, The Institute of Chartered Accountants of Scotland.

Aguinis, H., Glavas, A. (2012). What we know and don't know about corporate social responsibility: a review and research agenda. Journal of Management, 38, 932-968.

Bardin, L. (2009). Análise de conteúdo. Lisboa: Edições 70.

Barakat, S. R. (2013). Alinhamento entre estratégia e responsabilidade social corporativa à luz da RBV. Anais do $X X X V I /$ Encontro do ANPAD, Rio de Janeiro-RJ.

Barbieri, J. C. \& Cajazeira, J. E. R. (2009). Responsabilidade social empresarial e empresa sustentável: da teoria à prática. São Paulo: Saraiva.

Bayoud, N. S., Kavanagh, M. \& Slaughter, G. (2010). Factors influencing levels of corporate social responsibility disclosure by Libyan firms: a mixed study. International journal of Economics and Finance, 4(4), 13-29.

Birth, G., Illia, L., Lurati, F. \& Zaparini, A. (2008). Communicating CSR: practices among Switzerland's top 300 companies. Corporate Communications: An International Journal, 13(2), 182-196.

Branco, M. \& Rodrigues, L. (2006). Corporate social responsibility and resource based perspectives. Journal of Business Ethics, 69(2), 111-132.

Capriotti, P. \& Moreno, A. (2007). Corporate citizenship and public relations: the importance and interactivity of social responsibility issues on corporate websites. Public Relations Review, 33, 84-91. 
Carroll, A. B. (1979). A three dimensional conceptual model of corporate social performance. Academy of Management Review, 4(4), 497-505.

Carroll, A. B. (1991). The pyramid of corporate social responsibility: toward the moral management of organizational stakeholders. Business Horizons, July/August, p. 39-48.

Carroll, A. B. (1999). Corporate social responsibility. Business \& Society, 38(3), 268-295.

Chapple, W. \& Moon, J. (2005). Corporate social responsibility in Asia: a seven-country study of CSR web site reporting. Business and Society, 44(4), 415-441.

Chaudhri, V. \& Wang, J. (2007). Communicating corporate social responsibility on the internet: a case study of the top 100 information technology companies in India. Management Communication Quarterly, 21(2), $232-247$.

Cooper, D. R. \& Schindler, P. S. (2003). Métodos de pesquisa em administração. Porto Alegre: Bookman.

Davis, K. (1960). Can business afford to ignore social responsibilities? California Management Review, v. 2, p. 70-76.

Dawkins, J. \& Lewis, S. (2003). CSR in stakeholders' expectations and their implication for company strategy. Journal of Business Ethics, 44, 185-193.

Dias Filho, J. M. (2007). Políticas de evidenciação contábil: Um estudo do poder preditivo e explicativo da teoria da legitimidade. Anais XXXI EnANPAD, Rio de Janeiro-RJ.

Du, S., Bhattacharya, C. B. \& Sen, S. (2010). Maximizing business returns to corporate social responsibility (CSR): the role of CSR communication. International Journal of Management Reviews, 12(1), 8-19.

Ethos (2007). Público interno. In: Indicadores Ethos de Responsabilidade Social Empresarial. São Paulo: Instituto Ethos.

França, A. S. T., Favoretto, J. R. \& Braga, S. S. (2011). Estratégias de responsabilidade social das empresas na internet: uma análise comparativa dos conteúdos dos websites corporativos no Brasil. Revista de Gestão Social e Ambiental - RGSA, 5(3), 150-167.

Gil, A. G. (1989). Como elaborar projetos de pesquisa. 2. ed. São Paulo: Atlas.

Great Place To Work. GPTW - Melhores Empresas para Trabalhar Ceará. Disponível em <http://www.greatplacetowork.com.br/melhores-empresas/gptw-ceara>. Acesso em 5 dez. 2013.

Hair Jr. J. F., Babin, B., Money, A. H. \& Samouel, P. (2005). Fundamentos de métodos de pesquisa em administração. Porto Alegre: Bookman.

Hamayoun, S., Rahman, R. A., Johansson, J. \& Malmstron, M. (2012). Internet corporate social responsibility disclosure among Malaysian listed companies. Bioinfo Financial Management, 2(1), 42-50.

Hopkins, M. (2007). Corporate social responsibility and international development: is business the solution? London; Sterling, VA: Earthscan.

Hosmer, D. W. \& Lemeshow, S. (1989). Applied logistic regression. New York: John Wiley \& Sons.

Garriga, E. \& Melé, D. (2004). Corporate social responsibility theories: mapping the territory. Journal of Business Ethics, 53, 51-71.

Giavina-Bianchi, D. \& Pinedo, A. (2012). Como a cidadania corporativa pode fortalecer uma marca. Harvard Business Review Brasil, 90(4), abr.

Harrison, J. S. (2005). Administração estratégica de recursos e relacionamentos. São Paulo: Bookman.

Jahdi, K. S. \& Acikdilli, G. (2009). Marketing communications and corporate social responsibility: marriage of convenience or shotgun wedding. Journal of Business Ethics, 103-113.

Keller, K. L. (2003). Understanding brands branding and brand equity. Interactive Marketing, 5(1), 7-20.

Kim, D. \& Nam, Y. (2012). Corporate relations with environmental organizations represented by hyperlinks on the Fortune Global 500 companies' websites. Journal of Business Ethics, 105, 475-487.

Kotler, P. \& Caslione, J. A. (2008). Vencer no caos: lições para uma gestão eficaz em tempos de turbulência. Rio de Janeiro: Campus.

Lantos, G. P. (2001). The boundaries of strategic corporate social responsibility. Journal of Consumer Marketing, $18(7), 595-632$.

Laville, E. (2009). A empresa verde. São Paulo: Ote.

Maignan, I. \& Ferrell, O. C. (2004). Corporate social responsibility and marketing: an integrative framework. Journal of the Academy of Marketing Science, 32(1), 3-19. 
Meyskens, M. \& Paul, K. (2010). The evolution of corporate social reporting practices in Mexico. Journal of Business Ethics, 91, 211-227.

Mohammed, R., Alwi, K. \& Jamil, C. Z. M. (2010). Sustainability disclosure among Malaysian Shari'ah-Compliant listed companies: web reporting. Issues in Social and Environmental Accounting, 3(2), 160-179.

Morsing, M.; Schultz, M. (2006). Corporate social responsibility communication: stakeholder information, response and involvement strategies. Business Ethics: A European Review, vol. 16(4), pp. 323-338.

Patten, D. M. \& Crampton, W. (2004). Legitimacy and the internet: an examination of corporate web page environmental disclosures. Advances in Environmental Accounting and Management, 2, 31-57.

Pearce II, J. A. \& Doh, J. P. (2005). The high impact of collaborative social initiatives. MIT Sloan Management Review, 46(3), 30-39.

Scarlett, A. (2011). Communicating corporate social responsibility: challenges to companies with low company cause fit. A capstone project presented to the Faculty of the School of Communication, American University, for the degree of Masters of Arts in Public Communication. Washington D. C., April 26.

Schlegelmilch, B. B. \& Pollach I. (2005). The perils and opportunities of communicating corporate ethics. Journal of Marketing Management, 34(21), 267-290.

Silva, A. H. C. \& Sancovschi, M. (2006). Evidenciação social corporativa: estudo de caso da Empresa Petróleo Brasileiro S.A. Anais do XXX EnANPAD, Salvador/BA.

Sisodia, R. S., Sheth, J. N. \& Wolfe, D. B. (2008). Os segredos das empresas mais queridas. Bookman.

Sousa-Filho, J. M., Wanderley, L. S. O. \& Farache, F. (2010). Websites corporativos na comunicação de responsabilidade social em distribuidoras de energia: um estudo longitudinal. Pretexto, 11, 72-89.

Sousa-Filho, J. M., Abreu, M. C. S. \& Wanderley, L. S. O. (2007). Governança da responsabilidade social e vantagem competitiva: o caso Petrobras/Lubnor. Anais do X SEMEAD - Seminários em Administração FEA-USP.

Spitzeck, H., Hansen, E. G. \& Alt, E. (2011). Impactos do engajamento das empresas com seus stakeholders. DOM - Revista da Fundação Dom Cabral, 5(15), 28-33.

Stanley, C. A. (2011). A urgência da inovação. HSM Management, 5(88), set./out.

Tang, L. \& Li, H. (2009). Corporate social responsibility communication of Chinese and global corporations in China. Public Relations Review, 35, 199-212.

Vance, P. S., Angelo, C. F. (2007). Reputação corporativa: uma revisão teórica. Revista de Gestão (Rege-USP), 15, Disponível em http://www.usp.br/rege/ojs/index.php/rege/article/view/313 Acesso em 17 de outubro de 2013.

Zyglidopoulos, S. C. (2001). The impact of accidents on firm's reputation for social performance. Business \& Society, v. 40, n. 4, p. 416-441.

Wanderley, L. S. O., Lucian, R., Farache, F. \& Sousa Filho, J. M. (2008). CSR information disclosure on the web: a context-based approach analysing the influence of country of origin and industry sector, Journal of Business Ethics, 82, 369-378.

Wang, J. \& Chaudhri, V. (2009). Corporate social responsibility engagement and communication by Chinese companies. Public Relations Review, 35, 247-250.

Wood, D. J. (1991). Corporate social performance revisited. Academy of Management Review, 16(4), $691-718$.

Wurman, R. S. (2005). Ansiedade de informação 2. São Paulo: Cultura. 
APÊNDICE A

Lista de Melhores Empresas para se Trabalhar

\begin{tabular}{|c|c|c|}
\hline Empresa & Setor & Website \\
\hline 3 Corações & Pó de café & www.3coracoes.com.br \\
\hline Acal & $\begin{array}{l}\text { Material para construção, reforma e } \\
\text { ambientação }\end{array}$ & www.acalfortaleza.com.br \\
\hline Aliança & Transporte urbano & www.aliancatransportes.com.br \\
\hline Amêndoas do Brasil & Castanha de caju & www.amendoasdobrasil.com.br \\
\hline B\&Q Energia & $\begin{array}{l}\text { Empresa geradora de energia } \\
\text { privada }\end{array}$ & www.beq.com.br \\
\hline Beach Park & Parque aquático, hotel e resort & www.beachpark.com.br \\
\hline Casablanca Turismo & Agência de turismo & www.casablancaturismo.com.br \\
\hline Ceará Diesel & $\begin{array}{l}\text { Concessionária de veículos } \\
\text { Mercedes-Benz }\end{array}$ & www.cearadiesel.com.br \\
\hline Ceneged & $\begin{array}{l}\text { Prestação de serviços na área de } \\
\text { eletrificação e construção de redes } \\
\text { elétricas }\end{array}$ & www.ceneged.com.br \\
\hline Cerbras & Revestimentos cerâmicos & www.cerbras.com.br \\
\hline Cobap & $\begin{array}{l}\text { Empresa de papel e caixas de } \\
\text { papelão ondulado }\end{array}$ & www.cobap.com.br \\
\hline Coelce & Distribuição de Energia & www.coelce.com.br \\
\hline Conecta Serviços & $\begin{array}{l}\text { Empresa especializada em } \\
\text { recuperação de crédito }\end{array}$ & www.conecta.srv.br \\
\hline Construtora Marquise & $\begin{array}{l}\text { Empresa nas áreas de engenharia } \\
\text { de infraestrutura, incorporação, } \\
\text { serviços ambientais, finanças, } \\
\text { hotelaria, comunicação e shopping } \\
\text { center }\end{array}$ & www.marquise.com.br \\
\hline $\begin{array}{ll}\text { Cosampa } & \text { Projetos } \\
\text { Construções } & \end{array}$ & $\begin{array}{l}\text { Prestação de serviços nas áreas de } \\
\text { construção civil, engenharia } \\
\text { elétrica, elaboração de projetos e } \\
\text { energias renováveis }\end{array}$ & www.cosampa.com.br \\
\hline Consórcio Nacional Embracon & $\begin{array}{l}\text { Operadora de consórcio nacional de } \\
\text { imóvel, carros e motos }\end{array}$ & www.embracon.com.br \\
\hline Dafonte Veículos & $\begin{array}{l}\text { Concessionária de veículos } \\
\text { Chevrolet }\end{array}$ & www.dafonteveiculos.com.br \\
\hline Eficaz Engenharia e Serviços & $\begin{array}{l}\text { Prestadora de serviços do setor } \\
\text { elétrico }\end{array}$ & www.eficazengenharia.com.br \\
\hline Endicon Engenharia & $\begin{array}{l}\text { Soluções tecnológicas de } \\
\text { engenharia elétrica }\end{array}$ & www.endicon.com.br \\
\hline Fortbrasil & $\begin{array}{l}\text { Prestação de serviços financeiros e } \\
\text { administradora de cartões de } \\
\text { crédito próprio }\end{array}$ & www.fortbrasil.com.br \\
\hline Freelife Saúde & Plano de saúde & www.freelife.com.br \\
\hline Grupo Geppos & Restaurantes & www.grupogeppos.com.br \\
\hline Ibyte & Tecnologia da informação & www.ibyte.com.br \\
\hline $\begin{array}{l}\text { Instituto Dom José de Educação } \\
\text { e Cultura (IDJ) }\end{array}$ & $\begin{array}{l}\text { Educação e formação: coordenação } \\
\text { dos cursos da Universidade do Vale } \\
\text { do Acaraú - UVA }\end{array}$ & www.idj.com.br \\
\hline
\end{tabular}


Continuação...

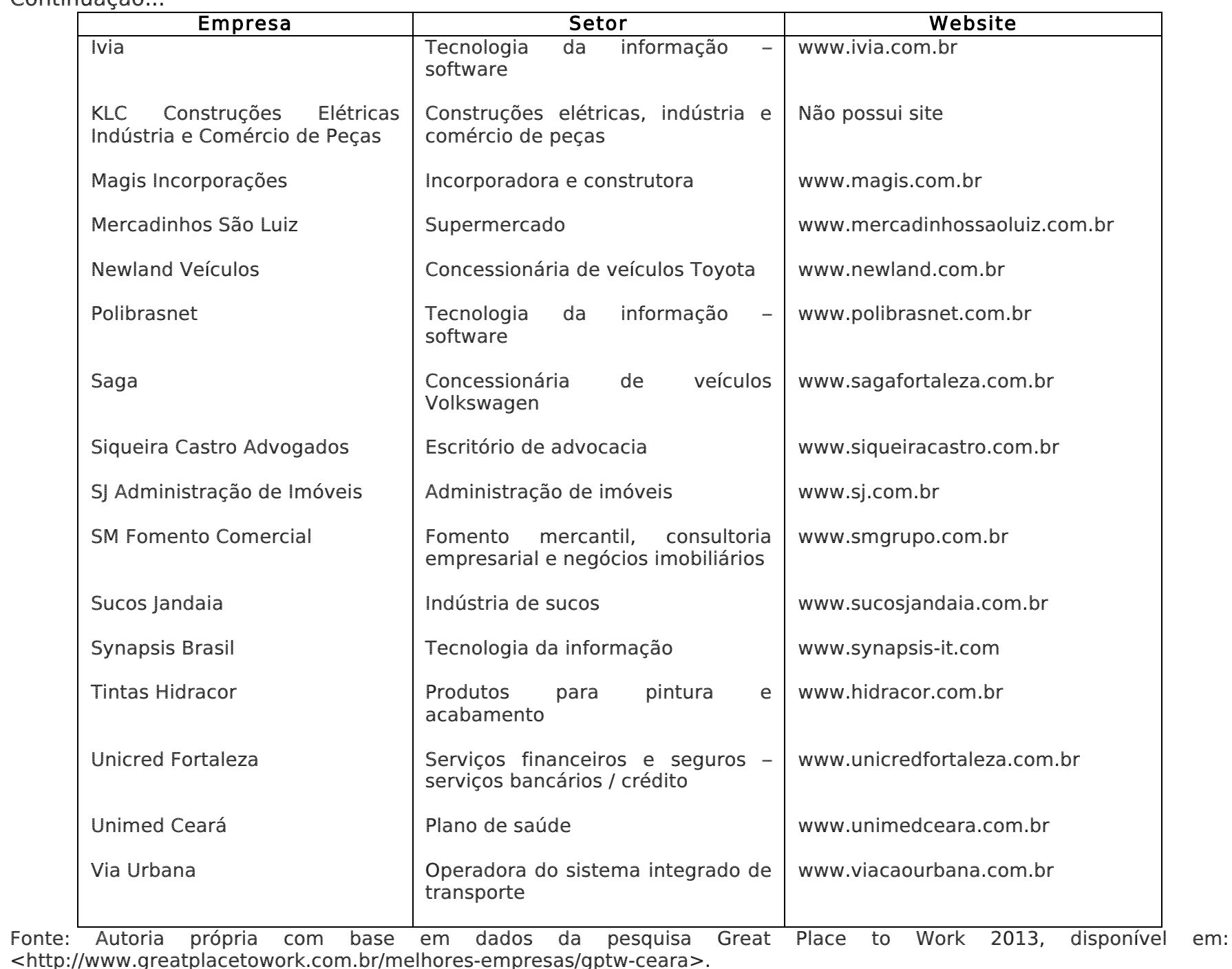

